\title{
Noninvasive prenatal testing for chromosome aneuploidies and subchromosomal microdeletions/ microduplications in a cohort of 42,910 single pregnancies with different clinical features
}

Yibo Chen ${ }^{1}$, Qi Yu ${ }^{1}$ Xiongying Mao ${ }^{1}$, Wei Lei ${ }^{2}$, Miaonan $\mathrm{He}^{3}$ and Wenbo Lu*

\begin{abstract}
Background: Since the discovery of cell-free DNA (cfDNA) in maternal plasma, it has opened up new approaches for non-invasive prenatal testing. With the development of whole-genome sequencing, small subchromosomal deletions and duplications could be found by NIPT. This study is to review the efficacy of NIPT as a screening test for aneuploidies and CNVs in 42,910 single pregnancies.

Methods: A total of 42,910 single pregnancies with different clinical features were recruited. The cell-free fetal DNA was directly sequenced. Each of the chromosome aneuploidies and the subchromosomal microdeletions/ microduplications of PPV were analyzed.

Results: A total of 534 pregnancies (1.24\%) were abnormal results detected by NIPT, and 403 pregnancies had underwent prenatal diagnosis. The positive predictive value (PPV) for trisomy 21(T21), trisomy 18 (T18), trisomy 13 (T13), sex chromosome aneuploidies (SCAs), and other chromosome aneuploidy was 79.23\%, 54.84\%, 13.79\%, $33.04 \%$, and $9.38 \%$ respectively. The PPV for CNVs was $28.99 \%$. The PPV for CNVs $\leq 5 \mathrm{Mb}$ is $20.83 \%$, for within 5-10 $\mathrm{Mb} 50.00 \%$, for $>10 \mathrm{Mb} 27.27 \%$ respectively. PPVs of NIPT according to pregnancies characteristics are also different. Conclusion: Our data have potential significance in demonstrating the usefulness of NIPT profiling not only for common whole chromosome aneuploidies but also for CNVs. However, this newest method is still in its infancy for CNVs. There is still a need for clinical validation studies with accurate detection rates and false positive rates in clinical practice.
\end{abstract}

Keywords: Noninvasive prenatal testing (NIPT), Chromosome aneuploidies, Microdeletion/microduplication syndromes (MMS), Clinical features, Positive predictive value (PPV)

\footnotetext{
* Correspondence: 13957874007@163.com

'Ningbo Women and Children Hospital, No.339, Liuting Street, Haishu District

Ningbo, Ningbo 315010, China

Full list of author information is available at the end of the article
}

(c) The Author(s). 2019 Open Access This article is distributed under the terms of the Creative Commons Attribution 4.0 International License (http://creativecommons.org/licenses/by/4.0/), which permits unrestricted use, distribution, and reproduction in any medium, provided you give appropriate credit to the original author(s) and the source, provide a link to the Creative Commons license, and indicate if changes were made. The Creative Commons Public Domain Dedication waiver (http://creativecommons.org/publicdomain/zero/1.0/) applies to the data made available in this article, unless otherwise stated. 


\section{Introduction}

Since the discovery of cell-free fetal DNA (cffDNA) in maternal plasma in 1997 [1], it has opened up new approaches for non-invasive prenatal testing (NIPT). Since 2011, massively parallel sequencing (MPS) for fetal aneuploidies has become available in more than 60 countries. NIPT using cfDNA circulating in maternal blood has opened the door to early, accurate, and safe prenatal testing, and it has been available clinically for over 8 years [2]. Weighted pooled detection rates and false-positive rates for screening for trisomy $21,18,13$, monosomy $\mathrm{X}$, and other sex aneuploidies are reported at 99.2\% (0.09\%), $96.3 \%$ (0.13\%), 91\% (0.13\%), 90.3\% (0.23\%), and 93\% (0.14\%) respectively [3]. A growing number of studies demonstrate that NIPT could reduce the incidence of unnecessary invasive procedures and iatrogenic fetal loss [4]. NIPT had many additional advantages over traditional biochemical and sonographic screening, such as higher sensitivities and specificities and ability to conduct NIPT at an earlier gestational age. In China, NIPT is recommended for screening trisomy 21 (T21), T18, and T13 for patients with high risk of serological screening results in the second trimester [5]. Now, more and more pregnant women are willing to choose NIPT $[6,7]$.

This newest method of prenatal screening has other applications, including screening for microdeletion/ microduplication syndromes (MMS) caused by copynumber variants $(\mathrm{CNVs})<10 \mathrm{Mb}$. MMS are individually rare, but together account for $1-2 \%$ of all newborn congenital abnormalities and often resulting in a severe burden for families and society. More recently, further development and expansion of NIPT has focused on MMS, such as $\mathrm{Hu}$ et al. [8] and Liang et al. [9] demonstrated NIPT performed well in some MMS.

However, there are many problems and challenges in clinical practice, and extensive validation is needed to determine accurately its detection rate and false-positive rate. The study's objective is to review the efficacy of NIPT as a screening test for aneuploidies and CNVs in 42,910 single pregnancies.

\section{Results}

Patient characteristics

From April 2015 to December 2018, a total of 42,931 maternal blood samples were collected from Ningbo Women and Children Hospital in China. In 21 cases, detection failed, with a failure rate of $0.05 \%$. Thus, the total sample included in this study was 42,910 . The pregnancy gestations were $12^{+0} \sim 26^{+6}$, the years of age were 18-49, and there were 10,742 women with advanced maternal age (age $\geq 35$ years). Clinical characteristics of the 42,910 cases are shown in Table 1. Of those 42,910 samples, there were 348 pregnant women who needed resampling due to low fetal DNA concentration in plasma; thus, the resampling rate was $0.81 \%(348 / 42910)$, and all the resamplings obtained a NIPT result (Table 1 ).

\section{Prenatal test results of total pregnant}

Before NIPT, pregnant women conventionally conducted screening test involving fetal ultrasonography (including color ultrasound and three dimension color ultrasound) and maternal serum biomarkers determination. Ultrasonography showed that 202 (0.47\%) fetuses were structurally abnormal, and there were 5749 (13.4\%) fetuses with an increased NT (NT $\geq 3 \mathrm{~mm}$ ). Maternal serum biomarkers determination suggested there were 2318 (5.4\%) high risk pregnancies and 15,863 (36.97\%) critical risk pregnancies; 8024 (18.70\%) pregnancies had no clinical indications (Table 1).

\section{NIPT results for T21, T18, T13, and SCAs}

The flowchart is shown in Fig. 1. A total of 42,931 samples were recruited with 42,910 NIPT results, including

Table 1 Clinical characteristic of pregnant women undergoing NIPT

\begin{tabular}{lll}
\hline Gestational age at NIPT (weeks) & No./N=42910 & $1 \%$ ) \\
\hline $12 \sim 15^{+6}$ & 5535 & 57.90 \\
$16 \sim 19^{+6}$ & 24759 & 24.50 \\
$20 \sim 23^{+6}$ & 10513 & 4.90 \\
$24 \sim 26^{+6}$ & 2103 & Rate (\%) \\
Clinical features & No. & 0.47 \\
Fetal structural abnormalities by B-ultrasound & 202 & 13.4 \\
Increased NT & 5749 & 0.03 \\
Other & & 12 \\
High risk of serological screening & 2318 & 5.40 \\
Critical risk of serological screening & 15863 & 36.97 \\
Advance maternal age ( $\geq 35$ years) & 10742 & 25.03 \\
No clinical indications & 8024 & 18.70 \\
\hline
\end{tabular}

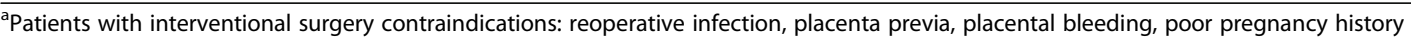




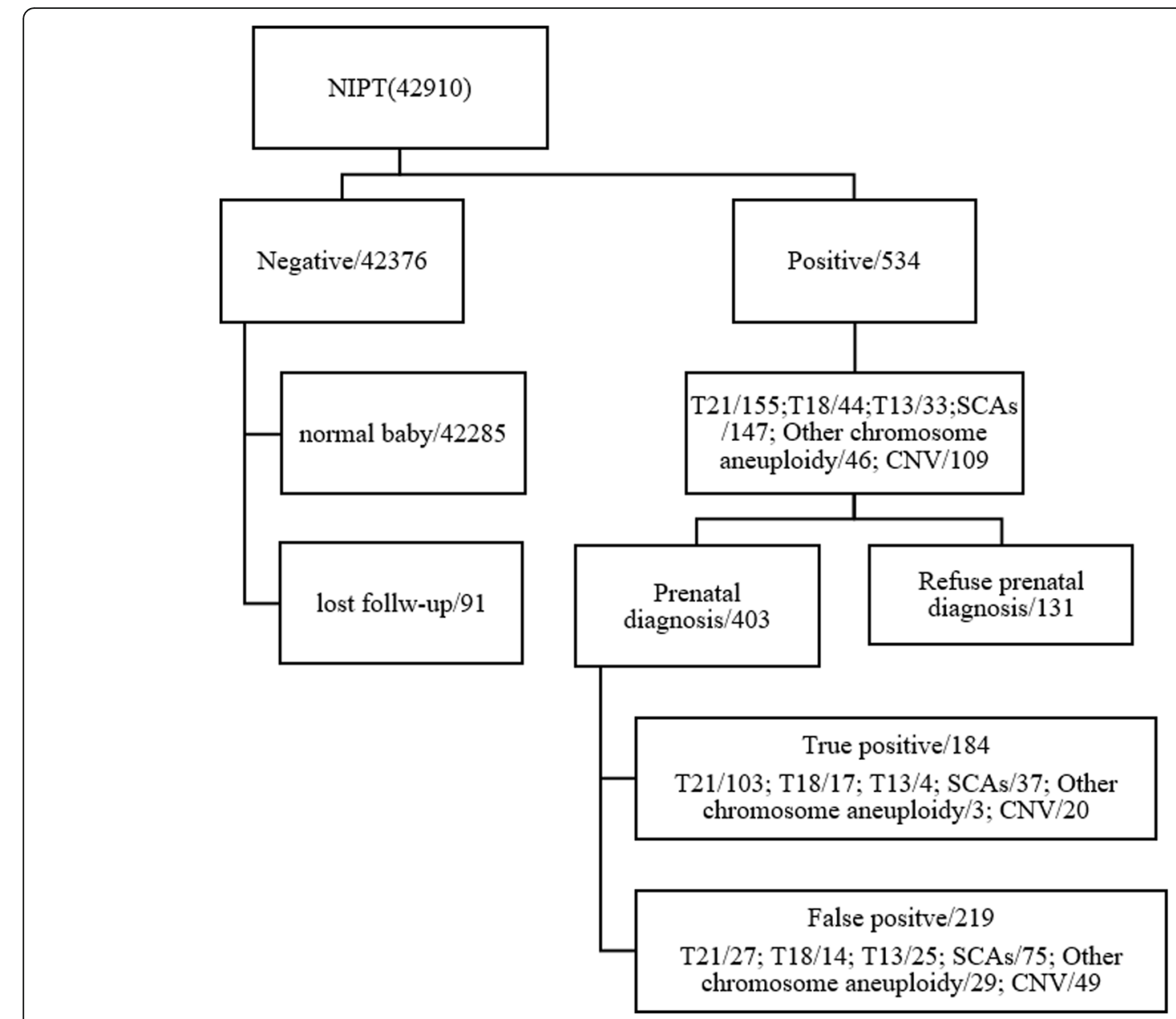

Fig. 1 Flowchart of non-invasive prenatal test (NIPT) results and clinical outcome of pregnant women

$534(1.24 \%)$ abnormal results. Of these 534 cases, there were 155 of trisomy 21 (T21), 44 of T18, 33 of T13, 147 of sex chromosome abnormalities (SCAs), 46 of other chromosome aneuploidy (except T21, T18, T13, and sex chromosome aneuploidy), and 109 of CNVs.

Karyotype was obtained to verify the abnormal results of the NIPT predictions. The total abnormal results of T21, T18, T13, and SCAs were 379. Of these 379, there were 302 cases underwent prenatal diagnostic testing, which confirmed 161 cases of true positive (103 cases of T21, 17 of T18, 4 of T13, 37 of SCAs) and 141 cases of false positive (FP). Moreover, the positive predictive value (PPV) for each test was assessed. For trisomy 21, the PPV was $79.23 \%$, for trisomy $18,54.84 \%$, for trisomy 13, 13.79\%, and for SCAs, 33.04\% (Table 2 and Fig. 1).

\section{NIPT results for CNVs and other chromosome aneuploidies}

Besides, we have also analyzed the CNVs and other chromosome aneuploidies, because this technology is genome-wide sequencing. The total cases of $\mathrm{CNVs}$ abnormal results are
109, including 20 true positive cases, 49 false positive cases, and 50 unverified cases. CNV number and size on each chromosome was assessed. CNVs were categorized into three groups according to length: $\mathrm{CNVs} \leq \mathrm{Mb}, \mathrm{CNVs}$ within 5-10 Mb, and CNVs > $10 \mathrm{Mb}$. The PPV for each group was also assessed. The total PPV for CNVs was $28.99 \%$. The PPV for $\mathrm{CNVs} \leq 5 \mathrm{Mb}$ is $20.83 \%$, for CNVs within $5-10 \mathrm{Mb}$ is $50.00 \%$, for $\mathrm{CNVs}>10 \mathrm{Mb}$ is $27.27 \%$ respectively. The total cases of other chromosome aneuploidy are 46, including 3 true positive, 29 false positive, and 14 unverified cases. The PPV for other chromosome aneuploidy was $9.38 \%$. In other chromosome aneuploidy, Chr7 aneuploidy is the largest group. All of Chr7 aneuploidy predicted by NIPT are trisomy 7 , but all verified patients (total number is 9) were confirmed to be false positives (Table 3 and Table 4).

\section{Different PPV according to pregnancies characteristics}

Different PPVs of NIPT according to pregnancies characteristics are shown in Table 5. The total PPV of T21 is 79.23\%, the PPV of T21 fetuses in women of advanced maternal age is $89.29 \%$, in high-risk of serological screening group is 
Table 2 Performance of non-invasive prenatal testing (NIPT) chromosome aneuploidy

\begin{tabular}{llllllll}
\hline NIPT & Trisomy 21 & Trisomy 18 & Trisomy 13 & SCAs & Other chromosome aneuploidy & CNVs & Total \\
\hline Positive & 155 & 44 & 33 & 147 & 46 & 534 \\
TP & 103 & 17 & 4 & 37 & 3 & 109 & 20 \\
FP & 27 & 14 & 25 & 75 & 29 & 494 \\
PPV & $79.23 \%$ & $54.84 \%$ & $13.79 \%$ & $33.04 \%$ & $9.38 \%$ & 219
\end{tabular}

TP true positive, FP false positive, PPV positive predictive value, SCAs sex chromosomal aneuploidies, CNV copy-number variations

$86.67 \%$, and in critical risk of serological screening group is $71.74 \%$, and the PPV of NIPT in increased NT group is the highest, which is $100 \%$. Similarly, the PPV in increased NT group is also the highest in predicting SCAs fetuses. It is worth noting that the PPVs of T18 fetuses in fetal structural abnormalities by B-ultrasound group, increased NT group, and high risk of serological screening are all $100 \%$, while in predicting T13 and CNVs in fetuses, the PPV of high risk of serological screening group and fetal structural abnormalities by $\mathrm{B}$-ultrasound group is the highest respectively.

\section{Discussion}

NIPT has been widely used for prenatal screening of $\mathrm{T} 21, \mathrm{~T} 18$, and T13 in the last few years. But, up to now, it is still lacking large scale clinical studies focused on the efficiency in subchromosomal copy number variations (CNVs), typically less than $5 \mathrm{Mb}$ in size $[8,9]$. Besides, there are really some concerns on the clinical performance $[10,11]$. Therefore, we hope that the present research including 42,910 cases can provide data support for these issues.

Table 3 The size and number of CNVs and other chromosome aneuploidies on each chromosome

\begin{tabular}{|c|c|c|c|c|c|c|c|c|c|c|c|}
\hline \multirow[t]{2}{*}{ Chr. } & \multicolumn{3}{|c|}{ CNVs length } & \multicolumn{4}{|l|}{ CNVs } & \multicolumn{4}{|c|}{ Other chromosome aneuploidies } \\
\hline & $\begin{array}{l}\leq 5 \\
\mathrm{Mb}\end{array}$ & $\begin{array}{l}\text { Within 5-10 } \\
\mathrm{Mb}\end{array}$ & $\begin{array}{l}>10 \\
\mathrm{Mb}\end{array}$ & $\begin{array}{l}\text { NIPT } \\
\text { positive }\end{array}$ & $\begin{array}{l}\text { NIPT true } \\
\text { positive }\end{array}$ & $\begin{array}{l}\text { NIPT false } \\
\text { positive }\end{array}$ & Unverified & $\begin{array}{l}\text { NIPT } \\
\text { positive }\end{array}$ & $\begin{array}{l}\text { NIPT true } \\
\text { positive }\end{array}$ & $\begin{array}{l}\text { NIPT false } \\
\text { positive }\end{array}$ & Unverified \\
\hline Chr1 & 0 & 0 & 1 & 1 & 1 & 0 & 0 & l & / & / & / \\
\hline Chr2 & 0 & 0 & 2 & 2 & 0 & 2 & 0 & / & / & / & / \\
\hline Chr3 & 0 & 0 & 2 & 2 & 0 & 0 & 2 & 2 & 0 & 2 & 0 \\
\hline Chr4 & 0 & 1 & 2 & 3 & 1 & 2 & 0 & 1 & 0 & 0 & 1 \\
\hline Chr5 & 0 & 1 & 2 & 3 & 0 & 1 & 2 & 1 & 1 & 0 & 0 \\
\hline Chr6 & 0 & 1 & 0 & 1 & 0 & 1 & 0 & I & / & I & / \\
\hline Chr7 & 3 & 1 & 6 & 10 & 1 & 8 & 1 & 14 & 0 & 9 & 5 \\
\hline Chr8 & 1 & 1 & 4 & 6 & 0 & 1 & 5 & 5 & 0 & 3 & 2 \\
\hline Chr9 & 0 & 0 & 4 & 4 & 0 & 1 & 3 & 2 & 0 & 1 & 1 \\
\hline Chr10 & 0 & 0 & 3 & 3 & 0 & 3 & 0 & 1 & 0 & 0 & 1 \\
\hline Chr11 & 0 & 0 & 5 & 5 & 1 & 2 & 2 & 1 & 0 & 1 & 0 \\
\hline Chr12 & / & / & I & / & / & I & / & 1 & 0 & 1 & 0 \\
\hline Chr13 & 2 & 2 & 4 & 8 & 2 & 3 & 3 & / & / & I & / \\
\hline Chr14 & 0 & 0 & 2 & 2 & 1 & 1 & 0 & 3 & 0 & 2 & 1 \\
\hline Chr15 & 2 & 1 & 0 & 3 & 1 & 1 & 1 & 2 & 1 & 1 & 0 \\
\hline Chr16 & 2 & 0 & 1 & 3 & 0 & 3 & 0 & 4 & 0 & 4 & 0 \\
\hline Chr17 & 3 & 1 & 0 & 4 & 0 & 3 & 1 & I & / & / & / \\
\hline Chr18 & 4 & 2 & 7 & 13 & 4 & 3 & 6 & I & / & / & / \\
\hline Chr19 & / & / & / & / & / & / & / & I & / & / & / \\
\hline Chr20 & 0 & 1 & 2 & 3 & 0 & 0 & 3 & 5 & 1 & 3 & 1 \\
\hline Chr21 & 0 & 0 & 1 & 1 & 1 & 0 & 0 & & / & / & / \\
\hline Chr22 & 9 & 0 & 5 & 14 & 2 & 8 & 4 & 4 & 0 & 2 & 2 \\
\hline $\begin{array}{l}X \text { or } \\
Y\end{array}$ & 11 & 5 & 2 & 18 & 5 & 6 & 7 & / & / & / & 0 \\
\hline Total & 37 & 17 & 55 & 109 & 20 & 49 & 40 & 46 & 3 & 29 & 14 \\
\hline
\end{tabular}


Table 4 The PPVs according to different CNV sizes

\begin{tabular}{llllll}
\hline CNV size & NIPT positive & TP & FP & Unverified & PPV (\%) \\
\hline$\leq 5 \mathrm{Mb}$ & 37 & 5 & 19 & 13 & 20.83 \\
Within 5-10 Mb & 17 & 6 & 6 & 5 & 50.00 \\
$>10 \mathrm{Mb}$ & 55 & 9 & 24 & 22 & 27.27 \\
Total & 109 & 20 & 49 & 40 & 28.99 \\
\hline
\end{tabular}

We used positive predictive value (PPV) to evaluate NIPT in this study. The PPV for T21 was 79.23\%, and for T18, T13; SCAs were $54.84 \%, 13.79 \%, 33.04 \%$ respectively. Besides, we also analyzed the PPV of other chromosome aneuploidy and CNVs. The PPV for other chromosome aneuploidy was $9.38 \%$, and for CNVs was $28.99 \%$. In several recent studies, the PPV range of T21 was $65-94 \%$, T18 was $47-85 \%$, and T13 was $12-62 \%$ [12-14]. Our results fall within this range. Interestingly, the PPV for CNVs was $28.99 \%$, obviously higher than that of T13. Previous clinical validation studies reported a variable performance for detection of specific MMS, with only low to moderate positive predictive values (PPVs) [9].

Recently, more relaxed guidelines have been suggested whereby screening for MMS can be performed routinely for younger women where microdeletions are more frequent than aneuploidies [15]. Based on its performance in this retrospective study of over 42,000 pregnancies, NIPT displays the hallmarks of a screening method suitable for MMS caused by CNVs. The PPV for CNVs within $5-10 \mathrm{Mb}$ is the highest $(50.00 \%)$ in this study, and PPV for CNVs $\leq 5 \mathrm{Mb}$ is the lowest (20.83\%). In Liang's paper (ref. [9]), the PPV for CNVs > $10 \mathrm{Mb}$ (32\%) and CNVs $<10 \mathrm{Mb}(19 \%)$ also were low but reasonable, indicating possible sufficient sensitivity and specificity of the test for potential screening of genome-wide fetal CNVs. PPV depends not only on the sensitivity and specificity of the assay, but also on the prevalence of the disease [16]. The PPV for CNVs $<10 \mathrm{Mb}$ is $31 \%$ in this study (data not shown in the table, PPV $=(5+6) /[(5+$
6) $+(19+6)])$, which is much higher than Liang's paper. In addition, a previous study reported an overall PPV for CNVs of 9.2\% [17], and the PPV in our study is much higher than that.

The PPVs for other chromosome aneuploidy were lower at $9.38 \%$ and similar to those reported also in Liang's paper (ref. [9]). The reason is that these aneuploidies are less prevalent and many of them have high rates of confined placental mosaicism (CPM). NIPT is performed using cell-free fetal DNA, and the primary source of cell-fetal DNA in the maternal circulation is thought to be apoptosis of placental cells from the cytotrophoblast [18], which is not always representative of the fetus. A situation in which a chromosomal abnormality occurs only in the placenta but not in the fetus is known as CPM [19] where observations of the incidence are around $1-2 \%[20]$. NIPT is a screening test. For precounseling for NIPT, women who choose should be well informed about the accuracy, reliability, false positive, and false negative rates. For post counseling, in regard to current NIPT guidelines, ACMG is strongly suggested to confirm by invasive prenatal diagnosis for all positive findings [21]. In addition, all women who carried a fetus suspected of having a confirmed pathogenic or likely pathogenic fetal chromosome anomaly were scheduled for a genetic counseling session to discuss pregnancy management options.

We have also made further thought about the different PPV of NIPT according to pregnancies characteristics, and the results in this section need more clinical data support. Different pregnancies characteristics show different PPV, and the PPV of NIPT is the highest for T21 and is much lower for other aneuploidies [22]. Advanced maternal age (usually $\geq 35$ years) is a high risk factor for T21. So, PPV in advanced maternal age is much higher than no clinical indications group. And PPV in high risk of serological screening group is higher than in critical risk group, which is consistent with Yu's paper [23],

Table 5 Different PPVs according to pregnancies characteristics

\begin{tabular}{|c|c|c|c|c|c|c|}
\hline Clinical features & $\begin{array}{l}\text { PPV of T21 } \\
(\%)\end{array}$ & $\begin{array}{l}\text { PPV of T18 } \\
(\%)\end{array}$ & $\begin{array}{l}\text { PPV of T13 } \\
(\%)\end{array}$ & $\begin{array}{l}\text { PPV of SCAs } \\
(\%)\end{array}$ & $\begin{array}{l}\text { PPV of other chromosome } \\
\text { aneuploidy (\%) }\end{array}$ & $\begin{array}{l}\text { PPV of CNVs } \\
(\%)\end{array}$ \\
\hline $\begin{array}{l}\text { Fetal structural abnormalities by B- } \\
\text { ultrasound }\end{array}$ & 0 & 100 & 0 & 0 & 0 & 100.00 \\
\hline Increased NT & 100 & 100 & / & 50.00 & 0 & 37.50 \\
\hline Other $^{a}$ & / & / & / & / & / & 0.00 \\
\hline High risk of serological screening & 86.67 & 100 & 100 & 28.57 & 12.50 & 11.11 \\
\hline Critical risk of serological screening & 71.74 & 33.33 & 9.09 & 28.57 & 0 & 50.00 \\
\hline Advanced maternal age ( $\geq 35$ years) & 89.29 & 60.00 & 9.09 & 30.77 & 15.38 & 5.26 \\
\hline No clinical indications & 33.33 & 0 & 25.00 & 35.71 & 0 & 41.67 \\
\hline Total & 79.23 & 54.84 & 13.79 & 33.04 & 9.09 & 28.99 \\
\hline
\end{tabular}

"/" indicates no data

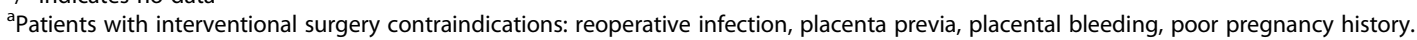


while advanced maternal age may not be a risk indication for T18 and T13. Similarly, unlike aneuploidy, the most common CNVs are not related to maternal age, so the PPV for advanced maternal age does not show a higher value.

$\mathrm{CNVs}$ have become increasingly recognized as significant contributors to human diseases [24], which are present in approximately $1.7 \%$ of all structurally normal pregnancies [25]. Chromosomal microarray analysis (CMA) is a powerful tool for the detection of invisible small chromosomal deletions or duplications and was recommended as a first-tier diagnostic tool for some patients with well-defined syndromes [26, 27]. However, CMA has many limitations. Because sampling of CMA requires invasive testing and invasive test are associated with risk [28], such as miscarriage, abortion, and intrauterine infection [29], or because it may identify variants of uncertain significance, some women may decline it. It has shown that NIPT detected subchromosomal copynumber variants (CNVs) performed well in some MMS [30], and in recent years, there have been quite a few reports on NIPT expanded for MMS [8, 9, 31]. But, NIPT is a screening test, there still a need for clinical validation on its accurate detection rates and false positive rates with a large number of clinical samples.

In the present study, follow-up is for negative results. According to the guideline of National Health Commission of the People's Republic of China, follow-up began at week 12 after delivery. Follow-up content should include the pregnancy outcomes of the subjects and the health of the newborn. The main follow-up content for newborn is whether the newborn is a T21 or T18 or T13 patient. Our follow-up began from 3 months after birth and strictly followed the national guideline in this study. At the time of follow-up, parents complained of neonatal with birth defects should go further genetic diagnosis. Besides, for CNVs, we have discussed the positive results, and we hope this study could provide validation for NIPT as a screening test for aneuploidies and CNVs.

\section{Conclusion}

In conclusion, this study involved a large prospective group of pregnant women with different clinical characters. The data have potential significance in demonstrating the usefulness of NIPT profiling not only for common whole chromosome aneuploidies but also for CNVs. However, this newest method is still in its infancy for CNVs. There is still a need for clinical validation studies with accurate detection rates and false positive rates in clinical practice.

\section{Materials and methods}

\section{Patients}

Pregnant women were collected consecutively. From April 2015 to December 2018, pregnant women who came to Ningbo Women and Children Hospital for prenatal examination were recruited. A total of 42,910 pregnant women were recruited. Prior to blood sampling, a signed consent form was obtained from each participant. Inclusion criteria were as follows: (1) pregnancy gestation period between $12^{+0} \sim 26^{+6}$, (2) single pregnancy, and (3) body mass index $(\mathrm{BMI})<100$. Exclusion criteria were as follows: (1) pregnant women with chromosomal abnormalities, (2) multiple pregnancy, (3) pregnant women who have received stem cell therapy and transplant surgery, (4) received allogeneic blood products within 1 year, and (5) received immunotherapy within 4 weeks.

\section{Serological screening and ultrasonography}

We used combined first trimester screening from 11 weeks to $13^{+6}$ weeks, and serological screening test was detected: the concentrations of AFP, free bHCG, and free E3 were detected by time-resolved immunofluorescence assay. NT was measured by a trained sonographer according to the Fetal Medicine Foundation protocol [32]. The risk values were calculated by Lifecycle software (4.0): high risk, T21 >1/300, T18 >1/350; intermediate risk, T21 $1 / 300$ to $1 / 1000$, T18 $1 / 350$ to $1 / 1000$; defining maternal age (AMA), maternal age $\geq 35$ years [23]; and defining NT $\geq 3 \mathrm{~mm}$ as increased NT [33].

\section{Sequencing}

Maternal peripheral blood $(5 \mathrm{ml})$ was collected in an ethylenediaminetetraacetic acid (EDTA) tube at a gestational age of $12^{+0}$ to $26^{+6}$ weeks. The blood sample was stored at $4{ }^{\circ} \mathrm{C}$ immediately after collection. Plasma was isolated within $8 \mathrm{~h}$ with a two-step centrifugation protocol according to the previous description (ref. [6]). The cell-free DNA extraction, library construction, sequencing, and bioinformatics analysis were performed according to the previous study (ref. [6]). High-throughput sequencing of fetal-free DNA fragments uses JingXin BioelectronSeq 4000 System (CFDA registration permit NO. 20153400309) semiconductor sequencer. Sequencing reads were filtered and aligned to the human reference genome (hg19). A combined GC correction and Zscore testing methods were used to identify fetal autosomal aneuploidy. Here, each chromosome with an absolute value of the Z-score greater than 3 was marked with chromosome aneuploidies or microdeletions/microduplications.

\section{Karyotype analysis and amniotic fluid puncture}

Women with positive NIPT results were recommended to receive karyotype analysis in amniotic fluid for further validation. The amniotic fluid puncture was performed as routinely described. The karyotype analysis was performed according to the International System for $\mathrm{Hu}$ man Cytogenetic Nomenclature guidelines [34]. 


\section{Follow-up for negative cases}

Follow-up investigation was performed to NIPT negative cases. According to the guideline of National Health Commission of the People's Republic of China, follow-up began at week 12 after delivery. Follow-up content should include the pregnancy outcomes of the subjects and the health of the newborn. The main follow-up content for newborn is whether the newborn is a T21 or T18 or T13 patient. Our follow-up began from 3 months after birth and strictly followed the national guideline in this study. At the time of follow-up, parents complained of neonatal with birth defects should go further genetic diagnosis. Patients lost to follow-up were excluded from the analysis.

\section{Statistical analysis}

Statistical analysis was used SPSS 20.0 software. Measurement data were expressed as mean \pm standard deviation $(x$ $\pm \mathrm{SD}$ ), count data adoption rate (\%), and positive predictive value $=$ true positive number/all positive cases.

\section{Abbreviations}

cfDNA: Cell-free DNA; CMA: Chromosomal microarray analysis; CNVs: Copynumber variants; MMS: Microdeletion/microduplication syndromes; NIPT: Non-invasive prenatal testing; NT: Nuchal translucency; PPV: Positive predictive value

\section{Acknowledgements}

Not available.

\section{Authors' contributions}

All authors have materially participated in the study and manuscript preparation. YC, QY, and XM collected all clinical data and carried out all the molecular genetic analyses. WL participated in the data analysis and drafted the manuscript. MH participated in the molecular genetic analyses. WL designed the work and drafted and revised the manuscript. All authors have approved the final article.

\section{Funding}

Zhejiang Medical and Health Science and Technology Plan Project (No. 2018KY720)

\section{Availability of data and materials}

The datasets used and/or analyzed during the current study are available from the corresponding author on reasonable request.

\section{Ethics approval and consent to participate}

This study was approved by the Ethics Committee of Ningbo Women and Children Hospital.

\section{Consent for publication}

The authors declare that they have no competing interests and the patients in this case report had provided their consent for publication.

\section{Competing interests}

The authors declare that they have no competing interests.

\section{Author details}

${ }^{1}$ Ningbo Women and Children Hospital, No.339, Liuting Street, Haishu District Ningbo, Ningbo 315010, China. ${ }^{2}$ CapitalBio Technology Inc., Beijing 101111, China. ${ }^{3}$ Beijing CapitalBio Medical Laboratory, Beijing 101111, China.
Received: 30 June 2019 Accepted: 15 November 2019

Published online: 29 November 2019

\section{References}

1. Lo, Y.M., et al., Presence of fetal DNA in maternal plasma and serum. 1997. 350(9076): p. 485-487.

2. Minear, M.A., et al., Global perspectives on clinical adoption of NIPT. 2015. 35(10): p. 959-967

3. Gil, M.M., et al., Analysis of cell-free DNA in maternal blood in screening for fetal aneuploidies: updated meta-analysis. 2015. 45(3): p. 249-266.

4. Zhang, $\mathrm{H}_{\text {, et al }}$ Non-invasive prenatal testing for trisomies 21, 18 and 13: clinical experience from 146,958 pregnancies. 2015. 45(5): p. 530-538.

5. McCullough RM, et al. Non-invasive prenatal chromosomal aneuploidy testing-clinical experience: 100,000 clinical samples. PLoS One. 2014;9(10):e109173.

6. $\mathrm{Hu}, \mathrm{H}_{\text {., }}$ et al., Clinical experience of non-invasive prenatal chromosomal aneuploidy testing in 190,277 Patient Samples. 2016. 16(8): p. - .

7. Mccullough, R.M., et al., Non-invasive prenatal chromosomal aneuploidy testing - clinical experience: 100,000 Clinical Samples. 2014. 9(10): p. e109173.

8. $\mathrm{Hu}, \mathrm{H}_{\text {., }}$ et al., Noninvasive prenatal testing for chromosome aneuploidies and subchromosomal microdeletions/microduplications in a cohort of 8141 single pregnancies. 2019. 13(1): p. 14.

9. Liang D, et al. Clinical utility of noninvasive prenatal screening for expanded chromosome disease syndromes. Genet Med. 2019.

10. Rose NC, Benn P, Milunsky A. Current controversies in prenatal diagnosis 1: should NIPT routinely include microdeletions/microduplications? Prenat Diagn. 2016;36(1):10-4

11. Evans, M.l., et al., Noninvasive prenatal screening or advanced diagnostic testing: caveat emptor. 2016. 215(3): p. 298-305.

12. Neofytou MC, et al. Targeted capture enrichment assay for non-invasive prenatal testing of large and small size sub-chromosomal deletions and duplications. PLoS One. 2017;12(2):e0171319.

13. Yaron $Y$, et al. Current status of testing for microdeletion syndromes and rare autosomal trisomies using cell-free DNA technology. Obstet Gynecol. 2015;126(5):1095-9.

14. Mary $\mathrm{E}_{\text {, et }}$ al. Cell-free DNA analysis for noninvasive examination of trisomy. N Engl J Med. 2015;372:1589-97.

15. Verma, I.C., R. Dua-Puri, and S.J.J.o.F.M. Bijarnia-Mahay, ACMG 2016 update on noninvasive prenatal testing for fetal aneuploidy: implications for India. 2017. 4(1): p. 1-6.

16. Lutgendorf, M.A., et al., Noninvasive prenatal testing: limitations and unanswered questions. 2014. 16(4): p. 281-285.

17. Schwartz, S., et al., clinical experience of laboratory follow-up with noninvasive prenatal testing using cell-free DNA and positive microdeletion results in 349 cases. 2018.

18. Tjoa, M.L., et al., Trophoblastic oxidative stress and the release of cell-free feto-placental DNA. 2006. 169(2): p. 400-404.

19. Mardy, A. and R.J.J.A.J.o.M.G.P.C.S.i.M.G. Wapner, Confined placental mosaicism and its impact on confirmation of NIPT results. 2016. 172(2): p. 118-122.

20. Grati, F.R., et al., Fetoplacental mosaicism: potential implications for false-positive and false-negative noninvasive prenatal screening results. 2014. 16(8): p. 620

21. Gregg, A.R., et al., Noninvasive prenatal screening for fetal aneuploidy, 2016 update: a position statement of the American College of Medical Genetics and Genomics. 2016. 18(10): p. 1056-1065.

22. Norton ME. et al. Cell-free DNA analysis for noninvasive examination of trisomy. 2015;372(17):1589-97.

23. $\mathrm{Yu}, \mathrm{B}$., et al., Overall evaluation of the clinical value of prenatal screening for fetal-free DNA in maternal blood. 2017. 96(27): p. e7114.

24. Girirajan, S., C.D. Campbell, and E.E.J.A.R.o.G. Eichler, Human copy number variation and complex genetic disease. 2011. 45(1): p. 203-226.

25. Wapner RJ, et al. Chromosomal microarray versus karyotyping for prenatal diagnosis. N Engl J Med. 2012;367(23):2175-84.

26. Miller, D.T., et al., Consensus statement: chromosomal microarray is a firsttier clinical diagnostic test for individuals with developmental disabilities or congenital anomalies. 2010. 86(5): p. 749-764.

27. Melanie, M. and H.J.G.i.M. Louanne, Array-based technology and recommendations for utilization in medical genetics practice for detection of chromosomal abnormalities. 2010. 12(11): p. 742-745.

28. Niederstrasser, S.L., et al., Fetal loss following invasive prenatal testing: a comparison of transabdominal chorionic villus sampling, transcervical chorionic villus sampling and amniocentesis. 2016. 37(S 01). 
29. Tabor A, Alfirevic Z. Update on procedure-related risks for prenatal diagnosis techniques. Fetal Diagn Ther. 2010;27(1):1-7.

30. Srinivasan A, et al. Noninvasive detection of fetal subchromosome abnormalities via deep sequencing of maternal plasma. Am J Hum Genet. 2013;92(2):167-76.

31. Martin K, et al. Clinical experience with a single-nucleotide polymorphismbased non-invasive prenatal test for five clinically significant microdeletions. Clin Genet. 2018;93(2):293-300.

32. Nicolaides, K.H., \%J American Journal of Obstetrics and Gynecology, Nuchal translucency and other first-trimester sonographic markers of chromosomal abnormalities. 2004. 191(1): p. 45-67.

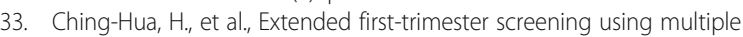
sonographic markers and maternal serum biochemistry: a five-year prospective study. 2014. 35(4): p. 296-301.

34. Gonzalez Garcia, J.R. and J.P.J.B. Mezaespinoza, International system for human cytogenetic nomenclature (ISCN). 2006. 108(12): p. 3952.

\section{Publisher's Note}

Springer Nature remains neutral with regard to jurisdictional claims in published maps and institutional affiliations.

Ready to submit your research? Choose BMC and benefit from:

- fast, convenient online submission

- thorough peer review by experienced researchers in your field

- rapid publication on acceptance

- support for research data, including large and complex data types

- gold Open Access which fosters wider collaboration and increased citations

- maximum visibility for your research: over $100 \mathrm{M}$ website views per year

At BMC, research is always in progress.

Learn more biomedcentral.com/submissions 